\title{
DOENÇA HEMORROIDÁRIA - ASPECTOS EPIDEMIOLÓGICOS E DIAGNÓSTICOS DE 9.289 PACIENTES PORTADORES DE DOENÇA HEMORROIDÁRIA
}

\author{
GERALDO MAGELA GOMES DA CRUZ', RENATA MAGALI RIBEIRO SILLUZIO FERREIRA ${ }^{1}$, \\ PETERSON MARTINS NEVES ${ }^{1}$
}

${ }^{1}$ Santa Casa de Belo Horizonte e Faculdade de Ciências Médicas de Minas Gerais, Minas Gerais, Brasil

CRUZ GMG, FERREIRA RMRS, NEVES PM. Doença Hemorroidária - Aspectos Epidemiológicos e Diagnósticos de 9.289 Pacientes Portadores de Doença Hemorroidária. Rev bras Coloproct, 2006;26(1): 6-23.

RESUMO: O objetivo deste trabalho é estudar 9.289 pacientes portadores de DH e 2.417 pacientes submetidos à hemorroidectomia, extraídos de um universo de $\mathbf{3 4 . 0 0 0}$ pacientes coloproctológicos examinados no decurso de 38 anos, analisando-se os dados epidemiológicos do diagnóstico e da cirurgia.

A incidência de DH como diagnóstico principal entre 34.000 pacientes foi de 27,3\% (9.289 pacientes), tendo 26,0\% (2.417 pacientes) deles sido submetidos a cirurgia.

Predominou, de forma estatisticamente significativa, a incidência de DH entre mulheres (5.007 : 9.289 ou 53,9\%) sobre homens (4.282 : 9.289 ou 46,1\%), da mesma forma que, mas sem significado estatístico, a incidência de cirurgias entre as mulheres portadoras de DH (1.330 : 5.007 ou 26,6\%) sobre cirurgias em homens portadores de DH (1.087 : 4.282 ou 25,4\%). Todavia, quando relacionada aos 2.417 pacientes operados, a incidência de cirurgia foi, de forma estatisticamente significativa, mais comum entre as mulheres ( $1.330: 2.417$ ou $55,0 \%$ ) que entre os homens (1.087 : 2.417 ou $45,0 \%$.

A média etária de diagnóstico foi de 39,9 anos, com 74,8\% entre 21 e 50 anos; e a média de cirurgia de 41,6 anos, com $71,8 \%$ entre 21 e 50 anos.

Os sintomas mais comuns foram presença de mamilos anais $(\mathbf{9 0 , 5 \%})$, sangue nas fezes $(83,0 \%)$, exteriorização pelo ânus ao ato defecatório $(\mathbf{7 1 , 0 \%})$, ardência anal $(54,0 \%)$, escape (soiling) $(\mathbf{4 4 , 0 \%})$ e sangue nas roupas $(41,0 \%)$. Predominou a DH de segundo $(28,3 \%)$, terceiro $(36,9 \%)$ e quarto graus $(20,3 \%)$, predominando a cirurgia na DH de terceiro grau $(30,5 \%)$, quarto grau $(60,2 \%)$ e plicomas anais $(30,9 \%)$.

A incidência de doenças anais concomitantes à $\mathrm{DH}$ foi de $12,1 \%$ (1.122 pacientes), destacando-se as fissuras anais $(5,8 \%)$ e a hipertrofia de papilas anais $(3,4 \%)$. A incidência de cirurgias para doenças anais concomitantes à $\mathrm{DH}$ no decurso das hemorroidectomias foi de $30,1 \%$ (729 pacientes), destacando-se as fissuras anais $(\mathbf{1 3 , 1 \%})$ e hipertrofia de papilas anais $(11,0 \%)$.

Descritores: Doença hemorroidária; hemorróidas; hemorroidectomia; epidemiologia; doenças anais.

Trabalho realizado no Serviço de Coloproctologia da Santa Casa de Belo Horizonte e Faculdade de Ciências Médicas de Minas Gerais. 
Rev bras Coloproct Janeiro/Março, 2006
Doença Hemorroidária - Aspectos Epidemiológicos e Diagnósticos de 9.289 Pacientes Portadores de Doença Hemorroidária Geraldo Magela Gomes da Cruz e Cols.

\section{INTRODUÇÃO}

HISTÓRICO: Desde a mais remota antigüidade (antigas civilizações grega e egípcia) o tema "hemorróidas" tem sido muito discutido, mas continua controverso sob determinados aspectos, quando o próprio termo que remonta a uma etimologia grega (Haemos $=$ sangue Rhoos $=$ derramar $)$, descreve um sintoma (sangramento) que nem sempre está presente, mesmo em casos avançados de prolapsos volumosos (Santos, $1999{ }^{34,35}$ ). Hipócrates, segundo citações da bibliografia, já descrevia, na antigüidade, a primeira hipótese etiopatogênica e fisiopatológica das hemorróidas: seriam estruturas vasculares que teriam a função de eliminar os "maus humores" do organismo através dos múltiplos episódios de sangramento. Muitos autores usam a designação de "doença hemorroidária" no lugar de "hemorróidas" querendo significar, com a última, a presença de mamilos internos ou externos, com ou sem sintomatologia; e, com a primeira, a presença de sintomas anais que levam o paciente ao proctologista. Doravante somente será usado o termo "doença hemorroidária" (DH).

Trata-se de uma doença intrigante, repleta de conceitos e preconceitos os mais variados, extremamente eivada de crendices que chegam até a escoadouros religiosos. Marcaram o tratamento desta doença muitos especialistas que a ela dedicaram com denodo, mas, sem querer desmerecer nenhum, alguns nomes ficaram ligados umbilicalmente a ela, destacando-se Ferguson, Milligan-Morgan, Parks e Whitehead.

ETIOPATOGENIA: São considerados, por vários autores 7, 8, 9, 10,15, 16, 22, 32, 34, 35, fatores etiopatogênicos de ordem predisponentes (hereditários, familiares e constitucionais ), e os fatores conjunturais desencadeantes (constipação intestinal, diarréias crônicas, esforços físicos repetitivos, gravidez, hábitos viciosos de trabalho e alimentares) que influenciam o desenvolvimento da $\mathrm{DH}$.

EPIDEMIOLOGIA: Há muita controvérsia sobre a epidemiologia da $\mathrm{DH}$, e vários trabalhos têm sido publicados com referência ao estudo da incidência absoluta de DH na população ${ }^{5,12,19,21,27,34,35,37}$. As disparidades decorrem do uso de metodologias completamente diversas, que vão desde a denominação de DH a doenças sintomáticas a achados fortuitos e mesmo achados de necropsias.
Embora a maioria dos autores admita predominância da DH no homem ${ }^{12,19,21,27,34,35}$, há relatos de incidências maiores no sexo feminino ${ }^{5,9,10 \text {, }}$ 12,37 .

São raríssimos relatos de ocorrências de DH na infância e muito pouco freqüentes antes dos 20 anos de idade, admitindo, a maioria dos autores 5, 12, 19, 21, 27, $34,35,37$ incidências mais elevadas entre 30 e 60 anos 5,9 . $10,12,18,19,21,22,23,27,34,35,37$.

Quanto à localização anatômica, a DH pode ser classificada em "internas" (submucosa anorretal acima do ligamento de Parks, recobertas por epitélio mucoso), "externas" (abaixo do ligamento de Parks, recobertas por pele modificada do canal anal) e "mistas" (extensões internas e externas), seja por autores que se dedicam a estudar a etiopatogenia $7,8,9$, $10,15,16,22,32,34,35$, seja por parte dos autores que apresentam grandes séries de pacientes com $\mathrm{DH}^{5,12 \text {, }}$ $19,21,27,34,35,37$.

Quanto à sintomatologia a DH é classificada em graus de evolução que se referem aos estágios de evolução das hemorróidas internas e partes internas das hemorróidas mistas: hemorróidas grau I (os coxins ou mamilos hemorroidários se apresentam congestos e intumescidos e podem sangrar sem haver exteriorização), hemorróidas grau II (os coxins ou mamilos internos se prolabam, projetando-se externamente ao ânus durante o esforço da defecação, entretanto recolhem-se espontaneamente após a cessação do esforço defecatório, podendo apresentar sangramento associado), hemorróidas grau III (os mamilos apresentam um volume maior e se prolabam mais facilmente com o esforço, de forma que o seu retorno à parte interna é sempre muito lento com auxílio de manobras manuais), hemorróidas grau IV (o volume dos mamilos e a flacidez dos tecidos são tão acentuados que o prolapso se torna incoercível, com a intitulada "perda de domicílio dos mamilos hemorroidários internos", que se apresentam permanentemente exteriorizados, apresentando macerações e erosões importantes do revestimento mucoso).

O diagnóstico é feito a partir da sintomatologia e do exame proctológico.Os sintomas mestres são o prolapso e o sangramento, mas, com o tempo, outros vão surgindo: sensações anorretais fora do ato defecatório (presença de mamilos anais, dermatite irritativa, dor em pontada, 
em ardência, latejante, em pressão; sensação de pressão retal, sensação de plenitude retal, secreção fecal, mucosa e sangue nas roupas), sensações ao ato defecatório (dificuldade), dor, exteriorização com redução espontânea ou manual, sensação de evacuação incompleta). O diagnóstico de $\mathrm{DH}$ ao exame proctológico não autoriza o final do exame, que deve ser completo - inspecção, apalpação, toque e retossigmoidoscopia além de manobras de esforço).

Dentre as complicações mais freqüentes podem ser destacados as tromboses, os estrangulamentos, as hemorragias e as ulcerações com infecção secundária e os abscessos 5, 7, 8, 9, 10, 12, 19, 21, 22, 27, $34,35,37$.

É comum a associação de DH com outras doenças anais, merecendo destaques as papilites, as criptites, as fissuras, as fístulas, os prolapsos, os pólipos inflamatórios reacionais 9, 10, 24, 25, 34, 35, 37 .

PATOGENIA: Durante muitos anos as hemorróidas foram consideradas "varizes das veias hemorroidárias". Outra teoria era a "teoria da hiperplasia vascular", apoiada na evidência dos vasos localizados na região anorretal, em virtude do grande afluxo de sangue no território das hemorróidas, simulando a aparência dos corpos cavernosos. Seguiuse a "teoria do deslizamento do assoalho anal", em decorrência de estudos anatomopatológicos do conteúdo hemorroidário identificarem degeneração do tecido conectivo fibroelástico na submucosa. Alguns autores ${ }^{8,15,16}$ afastaram algumas teorias ortodoxas, entre elas a teoria das veias varicosas e a teoria da hiperplasia vascular, através de minucioso estudo anatômico concluindo serem as hemorróidas verdadeiros coxins de tecido conjuntivo fibroelástico, ricos em plexos vasculares e com múltiplas anastomoses arteriovenosas, situados na submucosa da região anorretal, que se comportam como uma "almofada", ajudando na continência anal, permitindo a chamada "oclusão anal de repouso" ${ }^{34,35}$. Do ponto de vista etiopatogênico, o reconhecimento anatômico destes coxins reforça a teoria do "deslizamento do assoalho anal" proposta por Haas et al.(1983, 1984) ${ }^{15,16}$, que explica a evolução das hemorróidas ao longo das várias faixas etárias, com aparecimento dos sintomas em virtude da perda de elasticidade e da ruptura dos elementos estruturais de sustentação), devido aos fatores involutivos naturais que, sob a ação dos fatores desencadeantes de esforço, facultariam o referido deslizamento. Devem ser salientados, além destes fatores de sustentação ${ }^{34,35}$, os fatores vasculares e a micro-circulação dos plexos hemorroidários, assinalados por Copé (1994) ${ }^{7}$, além da elevação da pressão máxima de repouso ao nível do canal anal associada à presença de hemorróidas, enfatizada por Santos (1999) ${ }^{34,35}$.

CLASSIFICAÇ̃̃ O: Quanto à localização anatômica, a DH pode ser classificada em "internas" (submucosa anorretal acima do ligamento de Parks, recobertas por epitélio mucoso), "externas" (abaixo do ligamento de Parks, recobertas por pele modificada do canal anal) e "mistas" (extensões internas e externas). Quanto à disposição em torno do canal anal - uma vez que os dos vasos hemorroidários superiores seguem uma distribuição anatômica bem definida na grande maioria das pessoas, formando três "coxins" ou "mamilos" mais volumosos ou principais ou primários, situados na submucosa anorretal - os mamilos ou coxins distribuem-se nas posições lateral esquerdo, ântero-lateral direito e póstero-lateral direito (duas, cinco e nove horas, em analogia aos ponteiros do relógio afixado no períneo do paciente em posição genupeitoral) $9,10,32,34,35$.

COMPLICAÇ ÕES: entre as complicações mais freqüentes podem ser destacados as tromboses, os estrangulamentos, as hemorragias e as ulcerações com infecção secundária e os abscessos $9,10,24,25,34,35$, 37 .

DOENCAS ANAIS ASSOCIADAS: É comum a associação de DH com outras doenças anais, merecendo destaques, pela elevada incidência, as papilites, as criptites, as fissuras, as fístulas, os prolapsos, os pólipos inflamatórios reacionais, embora outras doenças mais raramente podem estar associadas, como os condilomas anais acuminados, as DST anorretais, a doença de Crohn ${ }^{5}$, os tumores, entre outras $9,10,24,25,34,35,37$.

\section{OBJETIVO}

O objetivo deste trabalho é estudar 9.289 pacientes portadores de DH, 2.417 dos quais submetidos à hemorroidectomia, analisando os dados epidemiológicos (incidência absoluta e relativa, sexo 
e idade), sintomatologia, exame proctológico, diagnóstico, e concomitância de outras doenças anorretais.

\section{CASUÍSTICA - PACIENTES E MÉTODO}

No decurso de 38 anos de profissão com prática totalmente centrada em Coloproctologia, o primeiro autor teve a oportunidade de formar um fichário constituído por 34.000 pacientes, tendo feito diagnóstico de $\mathrm{DH}$ como doença de fundo e motivo principal da consulta e dos sintomas, em 9.289 pacientes $(27,3 \%)$, tendo operado 2.417 deles.

Como o tempo de exercício profissional em que foram inseridos os 34.000 pacientes foi de 38 anos, significa que foram atendidos 894 pacientes por ano ou 74 pacientes ao mês ou 16 pacientes por semana, diagnosticando-se um caso de $\mathrm{DH}$ em cada 3,6 pacientes atendidos, como doença que motivou a consulta.

A facilidade de levantamento destes dados, na ausência de informatização do serviço, foi ensejada por um carimbo na face externa dos envelopes de prontuário dos pacientes portadores de $\mathrm{DH}$, em que constavam, na linha superior, os dados genéricos a serem coletados - Id (Idade), Se (Sexo), DgP (Diagnóstico Primário, DgS (Diagnóstico Secundário), Tr (Tratamento), An (Anestesia), Po (Posição), TeCi (Técnica Cirúrgica), EHP (Exame Histopatológico, além dos achados de hemorróidas), Co (Complicações), CiCo (Cirurgias Concomitantes)
(Tabela-1 superior) - , e na linha inferior, um exemplo de preenchimento de uma ficha: I (33 anos), S (F: feminino), DgP (HMGIV: hemorróidas mistas de quarto grau), DAC (FAP: fissura anal posterior), Tr (Ci: cirúrgico), An (AL: analgesia + local), Po (La: lateral ou Sims ${ }^{6}$ ), TeCi (Hab: hemorroidectomia aberta), CiCo (VMI: varicectomia de membros inferiores), EHP (SM: esquistossomose mansônica), SE (Gr: gravidez), Co (EA: estenose anal) - (Tabela-1 inferior).

\section{RESULTADOS}

INCID $\hat{E}$ NCIAABSOLUTA: A incidência de DH como diagnóstico principal entre 34.000 pacientes foi de $27,32 \%$ (9.289 pacientes), tendo $26,0 \%$ deles (2.417 pacientes) sido submetidos a tratamento cirúrgico da DH (Tabela-2 e Figura-1).

SEXO: Em relação aos 9.289 pacientes portadores de DH predominou, de forma estatisticamente significativa, a incidência de DH entre mulheres (5.007 : 9.289 ou 53,9\%) sobre homens (4.282 : 9.289 ou 46,1\%). Predominou, mas sem significado estatístico, a incidência de cirurgias entre as mulheres portadoras de DH (1.330: 5.007 ou 26,6\%) sobre cirurgias em homens portadores de DH (1.087 : 4.282 ou 25,4\%). Todavia, quando relacionada aos 2.417 pacientes operados, a incidência de cirurgia foi, de forma estatisticamente significativa, mais comum entre as mulheres (1.330: 2.417 ou 55,0\%) que entre

Tabela 1 - Teor do carimbo fonte dos dados de 9.289 envelopes contendo prontuários de pacientes portadores de doença hemorroidária $(\mathrm{DH})$ atendidos ao longo de 34 anos de exercício profissional e de 2.417 pacientes submetidos à hemorroidectomia (tabela superior, em negrito)*; e exemplo do preenchimento de um caso de um paciente (tabela inferior, sem negrito)**.

\begin{tabular}{|c|c|c|c|c|c|c|c|c|c|}
\hline I & $\mathbf{S}$ & DgP & DAC $\operatorname{Tr}$ & An & PO & Tci & CiCo & EHP & SE Co \\
\hline $\mathbf{I}$ & $\mathbf{S}$ & DgP & DAC $\mathrm{Tr}$ & An & Po & Tci & CiCo & EHP & SE Co \\
\hline 33 & $\mathrm{~F}$ & HMIV & FAP $\quad \mathrm{Ci}$ & $\mathrm{AL}$ & $\mathrm{La}$ & $\mathrm{Hab}$ & VMI & SM & Gr EA \\
\hline
\end{tabular}

(*) I (Idade), S (Sexo), DgP (Diagnóstico Primário), DAC (Doenças Anais concomitantes), $\boldsymbol{T r}$ (Tratamento), An (Anestesia), Po (Posição), TeCi (Técnica Cirúrgica), CiCo (Cirurgias Concomitantes), EHP (Exame Histopatológico, além dos achados de DH), SE (Situações especiais), Co (Complicações), (Tabela- 1 superior).

(**)I (33 anos), $\boldsymbol{S}$ (F: feminino), DgP (HMGIV: hemorróidas mistas de quarto grau), DAC (FAP: fissura anal posterior), $\boldsymbol{T r}$ (Ci: cirúrgico), An (AL: analgesia + local), Po (La: lateral ou Sims), TeCi (Hab: hemorroidectomia aberta), CiCo (VMI: varicectomia de membros inferiores), $\boldsymbol{E H P}$ (SM: esquistossomose mansônica), $\boldsymbol{S E}$ (Gr: gravidez), Co (EA: estenose anal) - (Tabela- 1 inferior). 


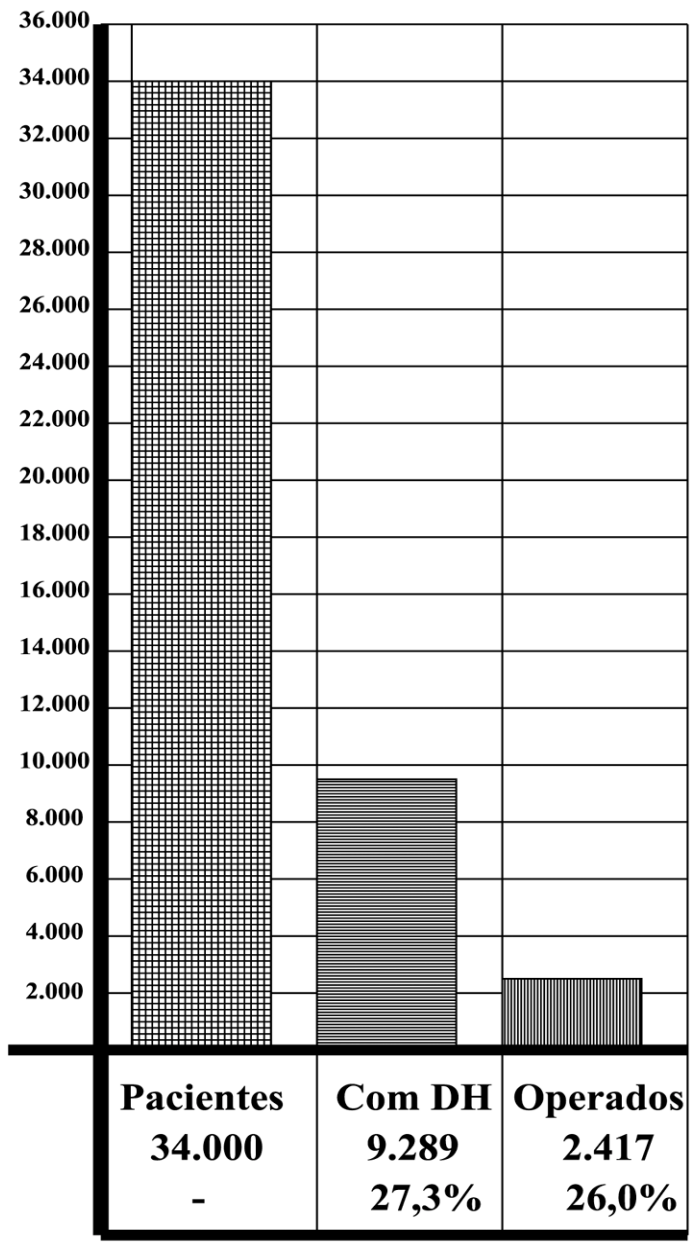

Figura 1 - Incidência de doença hemorroidária (DH) em um universo de 34.000 pacientes coloproctológicos: 9.289 casos (27,3\%) de $\mathrm{DH}$, dos quais 2.417 (26,0\%) foram submetidos à hemorroidectomia.

os homens (1.087 : 2.417 ou 45,0\% (Tabela-3 e Figuras-2 e 3 ).

IDADE: A Tabela-4 e a Figura-4 mostram a distribuição, por faixas etárias, da DH em 9.289 pacientes: $4,3 \%$ (401) na segunda década, $21,0 \%$ (1.957) na terceira, $30,4 \%$ (2.820) na quarta, $23,4 \%$ (2.172) na quinta, $11,7 \%$ (1.088) na sexta, 5,5\% (516) na sétima, 3,3\% (302) na oitava, $0,3 \%$ (27) na nona e $0,1 \%$ (6) na décima décadas. A média etária por ocasião do diagnóstico da DH foi 39,9 anos.

Por ocasião da cirurgia a média etária foi um pouco maior (41,6 anos), tendo sido a seguinte a distribuição etária por décadas (Tabela-4 e Figura-5): $0 \%$ (nenhum paciente) na primeira década, 5,6\% (137 pacientes) na segunda, 20,8\% (502 pacientes) na terceira, $28,5 \%$ (688 pacientes) na quarta, $22,5 \%$ (543 pacientes) na quinta, $11,3 \%$ (274 pacientes) na sexta, $6,3 \%$ (152 pacientes) na sétima, 4,5\% (110 pacientes) na oitava, $0,5 \%$ (11 pacientes) na nona e nenhum paciente na décima década.

Tabela 2 - Números absolutos e percentuais de pacientes examinados (34.000), pacientes portadores de DH (9.289) e pacientes submetidos à hemorroidectomia (2.417).

\begin{tabular}{lcc}
\hline Informações & $\mathbf{N}$ & $\%$ \\
\hline Total de pacientes atendidos & 34.000 & \\
Portadores de hemorróidas & 9.289 & $27,3 \%$ \\
Portadores de DH operados & 2.417 & $26,0 \%$ \\
\hline
\end{tabular}


Rev bras Coloproct Janeiro/Março, 2006
Doença Hemorroidária - Aspectos Epidemiológicos e Diagnósticos de 9.289 Pacientes Portadores de Doença Hemorroidária

Geraldo Magela Gomes da Cruz e Cols.
Vol. 26

Tabela 3 - Incidência absoluta $(N)$ e percentual (\%), por sexo, de 9.289 pacientes portadores de doença hemorroidária $(\mathrm{DH})$ e de 2.417 pacientes submetidos à hemorroidectomia.

\begin{tabular}{llcccc}
\hline Sexos & $\begin{array}{l}\text { N de } \\
\text { DH }\end{array}$ & $\begin{array}{c}\text { \% de } \\
\text { DH }\end{array}$ & $\begin{array}{c}\text { N operados } \\
\text { de DH }\end{array}$ & $\begin{array}{c}\text { \% operados relativo } \\
\text { ao N de DH }\end{array}$ & $\begin{array}{c}\text { \% de operados relativo } \\
\text { ao N de operados de DH }\end{array}$ \\
\hline Feminino & 5.007 & 53,9 & 1.330 & $26,6 \%$ & $55,0 \%$ \\
Masculino & 4.282 & 46,1 & 1.087 & $25,4 \%$ & $45,0 \%$ \\
Total & $\mathbf{9 . 2 8 9}$ & $\mathbf{1 0 0 , 0}$ & $\mathbf{2 . 4 1 7}$ & $\mathbf{2 6 , 0 \%}$ & $\mathbf{1 0 0 , 0 \%}$ \\
\hline
\end{tabular}
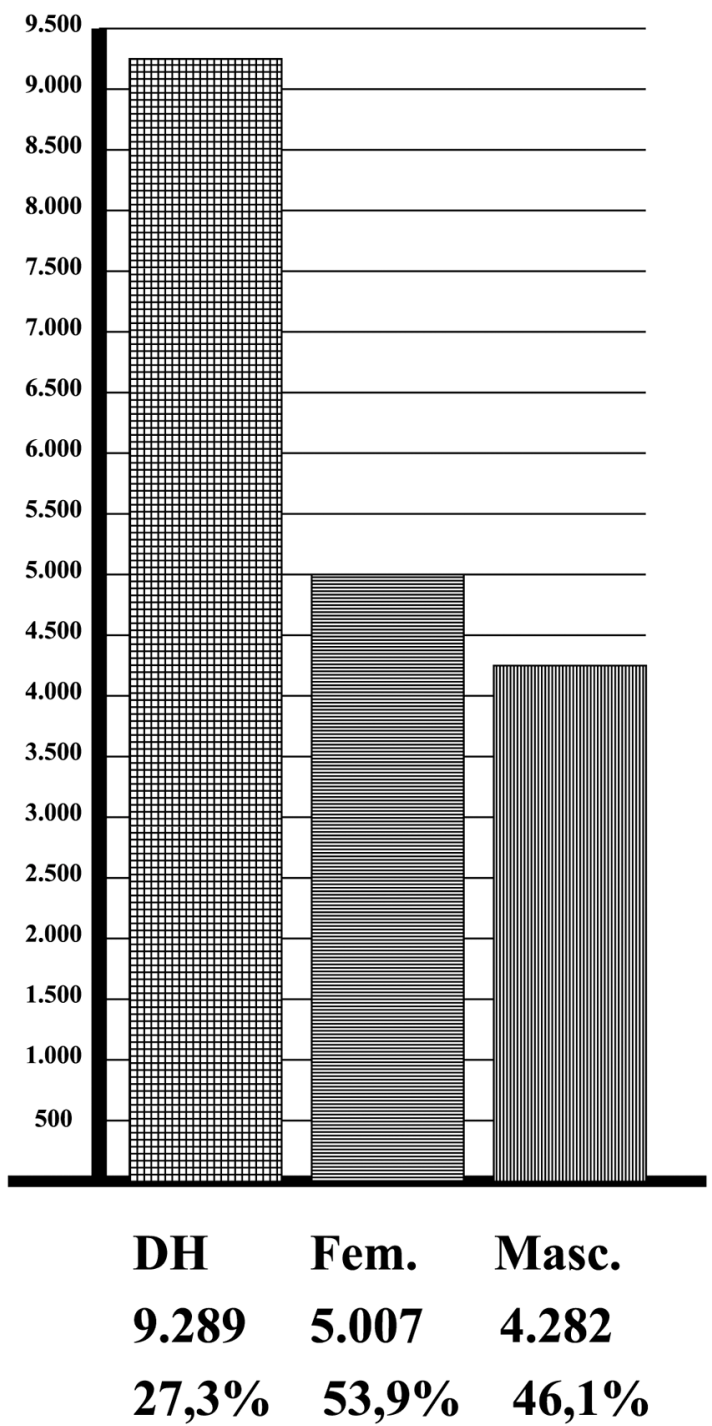

Figura 2 - Incidência absoluta e percentual de doença hemorroidária $(\mathrm{DH})$ nos sexos masculino e feminino: 5.007 casos de $\mathrm{DH}$ em mulheres $(53,9 \%)$ e 4.282 casos de $\mathrm{DH}$ em homens $(46,1 \%)$.

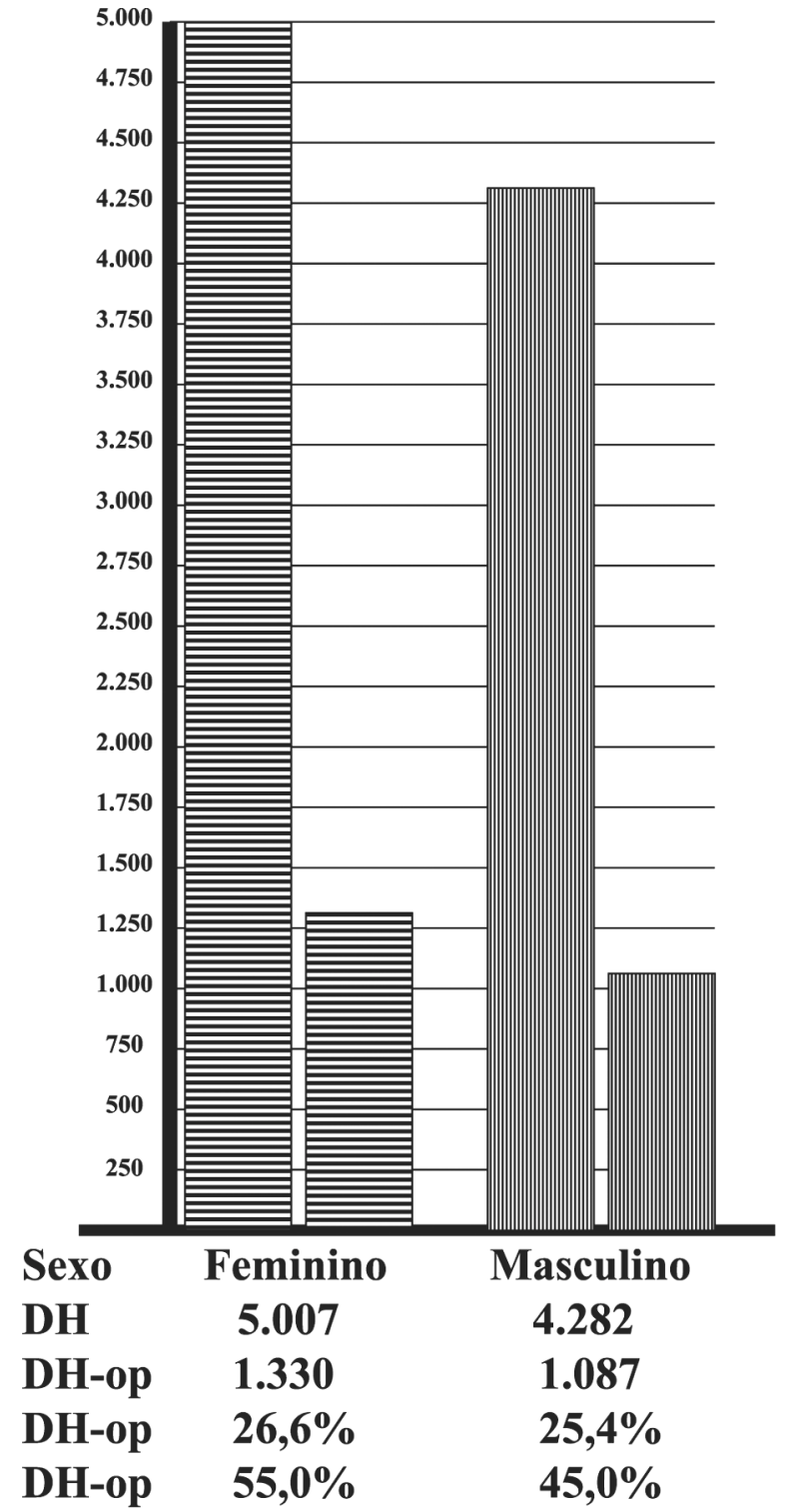

Figura 3 - Quadro comparativo das incidências absoluta e percentual de doença hemorroidária $(D H)$ e de hemorroidectomia no sexo masculino e feminino, em 9.289 pacientes portadores de DH e 2.417 operados. 
Rev bras Coloproct Janeiro/Março, 2006
Doença Hemorroidária - Aspectos Epidemiológicos e Diagnósticos de 9.289 Pacientes Portadores de Doença Hemorroidária

Geraldo Magela Gomes da Cruz e Cols.
Vol. 26
A Figura-6 exibe duas linhas representativas, para efeito de comparação, por décadas etárias (I), dos 9.289 pacientes portadores de $\mathrm{DH}$, representando "N-O" o número e “\%-O" o percentual de portadores de DH (linha contínua), e de 2.417 pacientes operados de $\mathrm{DH}$, representando

Tabela 4 - Distribuição, por décadas etárias, de 9.289 pacientes portadores de doença hemorroidária (DH) e de 2.417 pacientes submetidos à hemorroidectomia, em números absolutos $(N)$ e percentuais $(\%)$.

\begin{tabular}{lcccc}
\hline Faixas Etárias & N de DH & \% de DH & $\begin{array}{c}\text { N de Operados } \\
\text { de DH }\end{array}$ & $\begin{array}{c}\text { \% de Operados } \\
\text { de DH }\end{array}$ \\
\hline $1-10$ & 000 & & 000 & \\
$11-20$ & 401 & $4,3 \%$ & 137 & $5,6 \%$ \\
$21-30$ & 1.957 & $21,0 \%$ & 502 & $20,8 \%$ \\
$31-40$ & 2.820 & $30,4 \%$ & 688 & $28,5 \%$ \\
$41-50$ & 2.172 & $23,4 \%$ & 543 & $22,5 \%$ \\
$51-60$ & 1.088 & $11,7 \%$ & 274 & $6,3 \%$ \\
$61-70$ & 516 & $5,5 \%$ & 152 & $4,5 \%$ \\
$71-80$ & 302 & $3,3 \%$ & 110 & $0,5 \%$ \\
$81-90$ & 027 & $0,3 \%$ & 011 & $0 \%$ \\
$91-100$ & 006 & $0,1 \%$ & 000 & $\mathbf{1 0 0 , 0 \%}$ \\
Total & $\mathbf{9 . 2 8 9}$ & $\mathbf{1 0 0 , 0 \%}$ & $\mathbf{2 4 1 7}$ & \\
\hline
\end{tabular}

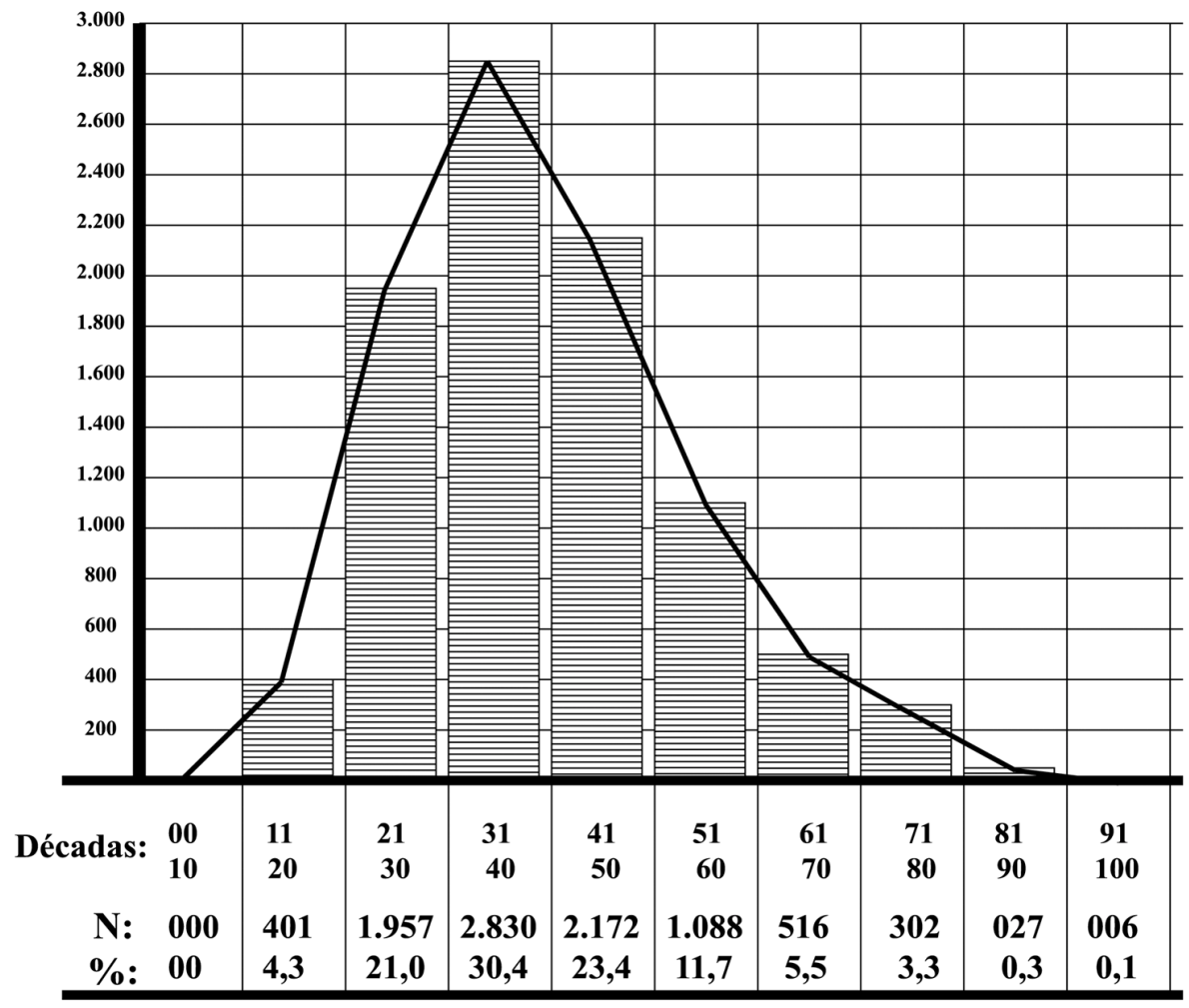

Figura 4 - Distribuição, por décadas etárias, de 9.289 pacientes portadores de doença hemorroidária (DH), em números absolutos ( $N)$ e percentuais (\%), sendo as colunas representativas unidas pela linha contínua, fluxo das décadas etárias por ocasião do diagnóstico. 
"N-O" o número e "\%-O" o percentual de portadores de DH operados (linha pontilhada): 4,3\% de portadores de DH para $5,6 \%$ de operados na segunda década; $21,0 \%$ de portadores de DH para $20,8 \%$ de operados na terceira década; $30,4 \%$ de portadores de DH para $28,5 \%$ de operados na quarta década; $23,4 \%$ de portadores de DH para 22,5\% de operados na quinta década; $11,7 \%$ de portadores de DH para $11,3 \%$ de operados na sexta década; $5,5 \%$ de portadores de DH para $6,3 \%$ de operados na sétima década; $3,3 \%$ de portadores de DH para 4,5\% de operados na oitava década; $0,3 \%$ (27) de portadores de DH para $0,5 \%$ de operados na nona década; e $0,1 \%$ de portadores de DH para nenhum operado na décima década.

SINTOMATOLOGIA: A Tabela 5 e a figura 7 mostram os sintomas mais comuns descritos pelos pacientes portadores de DH colhidos dos 200 últimos da série de 9.289 pacientes, descartando-se os que apresentavam outras doenças anais concomitantes (DAC): mamilos anais (181 casos, 90,5\%), sangue nas fezes (166 casos, $83,0 \%)$, exteriorização pelo ânus ao ato defecatório (142 casos, 71,0\%), ardência anal (112 casos, 54,0\%), escape (soiling) (88 casos, 44,0\%) e sangue nas roupas (62 casos, 41,0\%).

GRADAÇÃO DA DH: Foi a seguinte a distribuição dos vários graus dos 9.289 casos de $\mathrm{DH}$ por ocasião do diagnóstico: (Tabela 6 e Figura 8): primeiro grau em 1.135 pacientes $(12,2 \%)$, segundo grau em 2.625 pacientes $(28,3 \%)$, terceiro grau em 3.429 pacientes $(36,9 \%)$, quarto grau em 1.883 pacientes $(20,3 \%)$ e plicomas anais ou hemorróidas externas em 217 pacientes $(2,3 \%)$.

Foi a seguinte a distribuição das 2.417 cirurgias pela gradação da DH: $0 \%$ do primeiro grau (0 cirurgias em 1.135 pacientes); 6,5\% do segundo

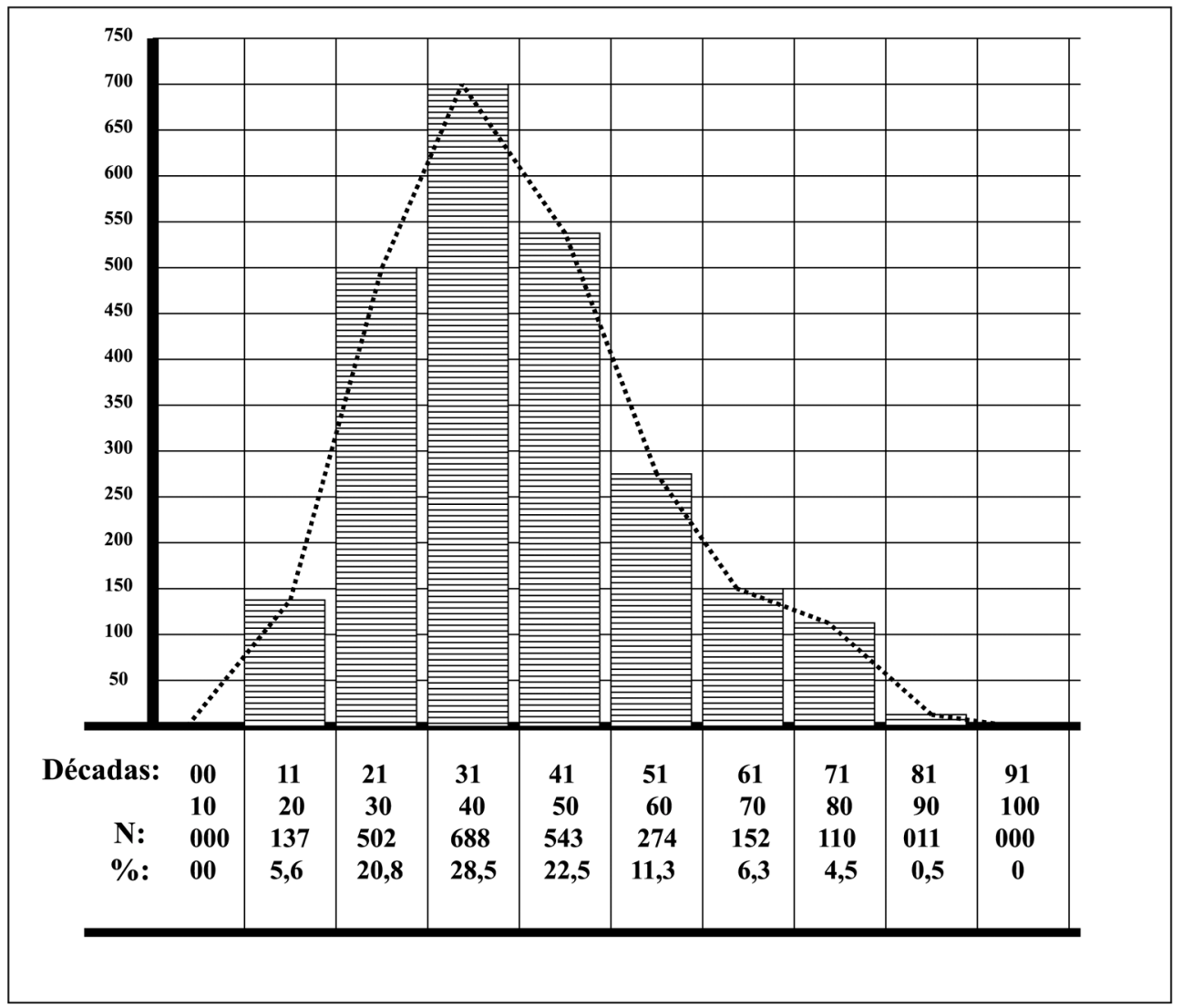

Figura 5 - Distribuição, por décadas etárias, de 2.417 pacientes operados de doença hemorroidária (DH), em números absolutos (N) e percentuais (\%), sendo as colunas representativas unidas pela linha pontilhada, fluxo das décadas etárias por ocasião da cirurgia. 
Rev bras Coloproct Janeiro/Março, 2006
Doença Hemorroidária - Aspectos Epidemiológicos e Diagnósticos de 9.289 Pacientes Portadores de Doença Hemorroidária Geraldo Magela Gomes da Cruz e Cols.
Vol. 26

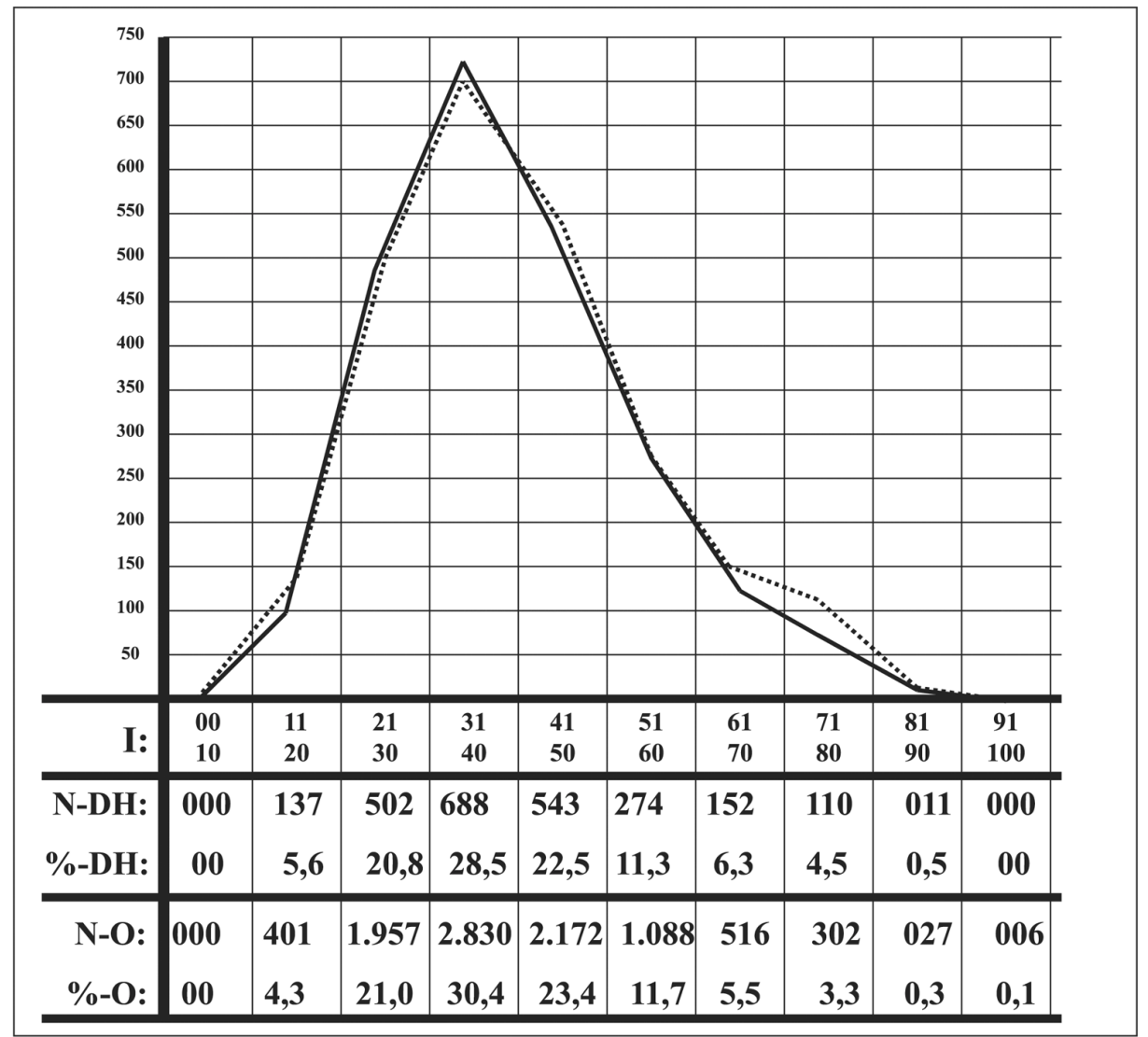

Figura 6 - Linhas representativas, para efeito de comparação, por décadas etárias (I), de 9.289 pacientes portadores de DH (linha contínua), em números absolutos $(\mathrm{N}-\mathrm{DH})$ e percentuais (\%-DH), e de 2.417 pacientes operados de DH (linha pontilhada), em números absolutos $(\mathrm{N}-\mathrm{O})$ e percentuais $(\%-\mathrm{O})$.

grau (170 cirurgias em 2.625 pacientes), $30,5 \%$ do terceiro grau (1.046 cirurgias em 3.429 pacientes), $60,2 \%$ do quarto grau (1.134 cirurgias em 1.883 pacientes) e $30,9 \%$ dos plicomas anais (67 cirurgias em 217 pacientes) (Tabela-6 e Figura-8).

Foi a seguinte a distribuição das várias formas de DH operadas (2.417 pacientes) em relação ao total de pacientes portadores de DH (9.289 pacientes): foram operados, dos 9.289 portadores de $\mathrm{DH}, 2.417$ pacientes $(26,0 \%)$, sendo $0 \%$ do primeiro grau, $1,8 \%$ do segundo grau (170 pacientes), $11,3 \%$ do terceiro grau (1.046 pacientes), $12,2 \%$ do quarto grau (1.134 pacientes operados) e $0,7 \%$ de plicomas anais ou hemorróidas externas (67 pacientes operados) (Tabela6 e Figura-8).

Foi a seguinte a distribuição dos vários graus de DH operadas em relação ao total de cirurgias para DH (2.417): dos 2.417 pacientes operados de DH, em
Tabela 5 - Sintomas decorrentes de doença hemorroidária (DH) colhidos dos 200 últimos pacientes da série de 9.289 portadores de DH (descartando-se os que apresentavam outras doenças anais concomitantes) a saber: mamilos anais, sangue nas fezes, exteriorização anal ao ato defecatório, ardência anal, soiling e sangue nas roupas, sendo " $N$ " o número e "\%" o percentual de pacientes com os sintomas assinalados.

\begin{tabular}{lll}
\hline Sintomas & N & \% \\
\hline Mamilos anais & 181 & $90,5 \%$ \\
Sangue nas fezes ou PH & 166 & $83,0 \%$ \\
Exteriorização ao AD & 142 & $71,0 \%$ \\
Ardência anal & 112 & $56,0 \%$ \\
Soiling & 88 & $44,0 \%$ \\
Sangue nas roupas & 62 & $31,0 \%$ \\
\hline
\end{tabular}



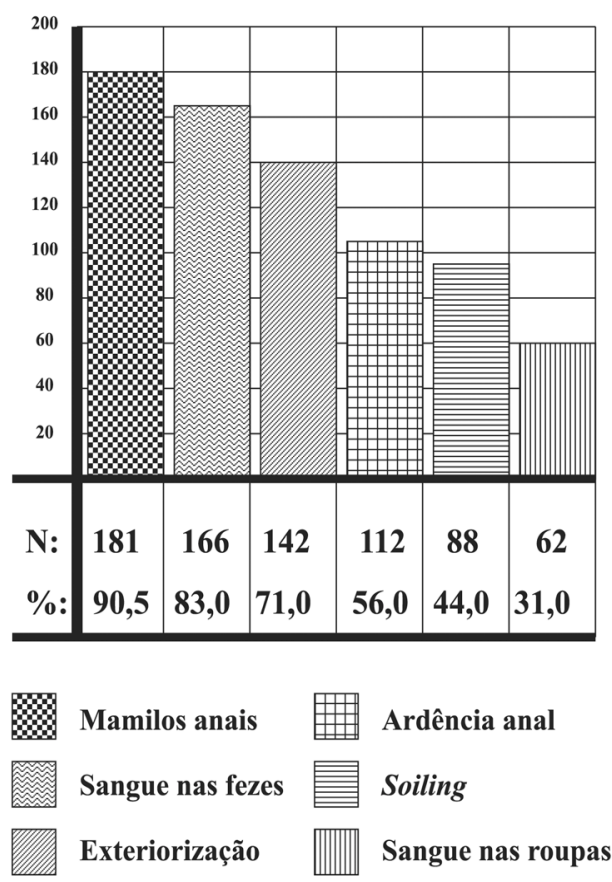

Figura 7 - Sintomas decorrentes de doença hemorroidária (DH) colhidos dos 200 últimos pacientes da série de 9.289 portadores de DH (descartando-se os que apresentavam outras doenças anais concomitantes.

relação aos vários graus de DH operadas, foi a seguinte a distribuição (Tabela-6 e Figura-8): grau I, nenhum paciente (0\%); grau II, 170 pacientes $(7,0 \%)$; grau III. 1.046 pacientes $(43,3 \%)$; grau IV, 1.134 pacientes (46,9\%); e plicomas anais, 67 pacientes $(2,8 \%)$.

Foi a seguinte a distribuição dos vários graus de DH operadas em relação aos próprios graus da $\mathrm{DH}$ : nenhum paciente entre os 1.135 portadores de $\mathrm{DH}$ de primeiro grau foi operado $(0 \%)$; dos 2.625 portadores de DH de segundo grau 170 foram operados $(6,5 \%)$; dos 3.429 pacientes portadores de $\mathrm{DH}$ de terceiro grau 1.046 foram operados $(30,5 \%)$; dos 1.883 pacientes portadores de $\mathrm{DH}$ de quarto grau 1.134 foram operados (60,2\%). E dos 217 pacientes portadores de plicomas anais 67 foram operados (30,9\%) (Tabela-6 e Figura-8).

INCIDENNCIA DE DOENCAS ANAIS CONCOMITANTES (DAC) (1.122 PACIENTES) À DH (9.289 PACIENTES): diagnósticos concomitantes ao diagnóstico da $\mathrm{DH}$, por ocasião do exame proctológico, como doenças paralelas ou secundárias, foram feitos em 1.122 pacientes $(12,1 \%)$ (Tabela-7 e
Figura-9), assim distribuídos: 541 casos $(5,8 \%)$ de fissura anal, $312(3,4 \%)$ de hipertrofia de papilas anais, $117(1,3 \%)$ de fístula anal, $112(1,2 \%)$ de hipotonia anal com incontinência parcial, $37(0,4 \%)$ e $3(0,03 \%)$ de tumores perianais.

Foi a seguinte a proporção entre cada DAC e os 1.122 casos de DAC à DH: 48,2\% (541 casos) eram fissuras anais, $27,8 \%$ (312 casos) eram hipertrofia de papilas anais, $10,4 \%$ (117 casos) eram fístulas anais, $10,0 \%$ (112 casos) eram hipotonia anal com incontinência parcial, 3,3\% (37 casos) eram condilomas anais acuminados e 0,3\% (3 casos) eram tumores anais malignos (Tabela-7 e Figura-9).

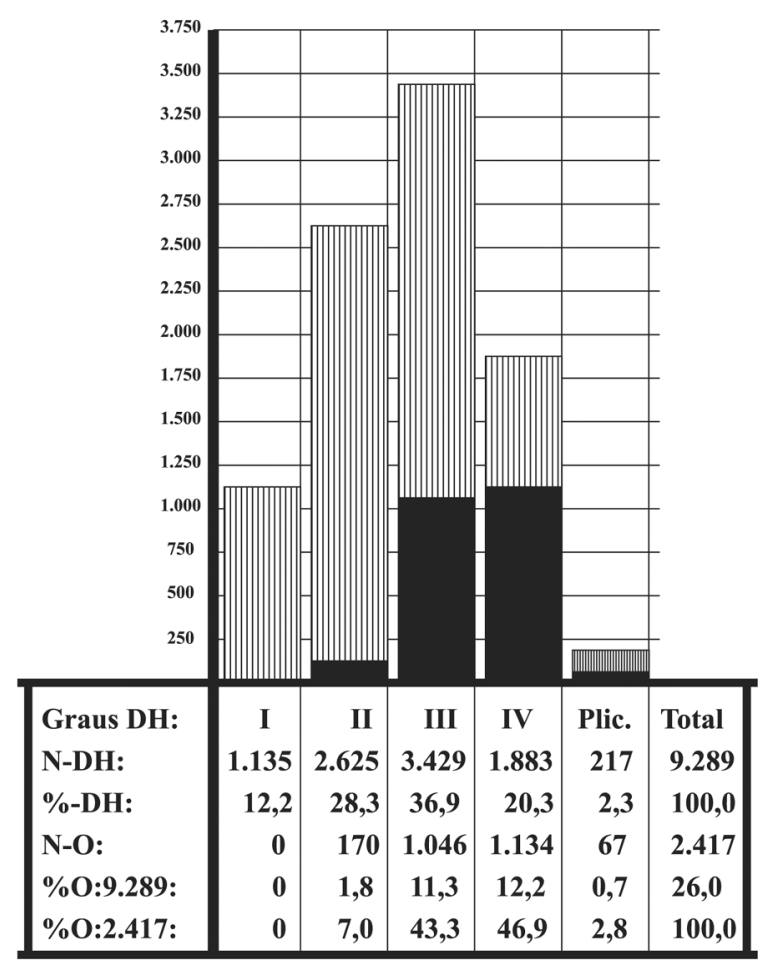

Figura 8 - Incidência dos vários graus de doença hemorroidária (DH) (grau I, grau II, grau III, grau IV e plicoma), em números absolutos ( N) e percentuais (\%), em relação aos 9.289 pacientes portadores de $\mathrm{DH}(\mathrm{N}-\mathrm{DH}$ e \%-DH), aos pacientes operados $(\mathrm{N}$ $O$ ), comparando-os aos 9.289 pacientes examinados (\%O:9.289) e aos 2.417 pacientes operados (\%0:2.417). As colunas listradas e em negrito referem-se, respectivamente, aos pacientes portadores de vários graus de $\mathrm{DH}$ e aos pacientes operados de vários graus de $\mathrm{DH}$. 
Tabela 6 - Incidência dos vários graus de DH (grau I, grau II, grau III, grau IV e plicoma), em números absolutos (N) e percentuais (\%), em relação aos 9.289 pacientes portadores de $\mathrm{DH}$, aos pacientes operados, comparandoos aos 9.289 pacientes com diagnóstico de DH e aos 2.417 pacientes operados; e incidência dos vários graus operados em relação aos graus de DH diagnosticados.

\begin{tabular}{|c|c|c|c|c|c|c|}
\hline $\begin{array}{l}\text { Graus } \\
\text { Da DH }\end{array}$ & N de $D H$ & $\%$ de DH & $\begin{array}{l}\mathrm{N} \text { de cirurgias } \\
\text { por } \mathrm{N} \text { de } \mathrm{DH}\end{array}$ & $\begin{array}{l}\text { \% cirurgias } \\
\text { pelos graus de } \\
\text { DH operadas }\end{array}$ & $\begin{array}{c}\% \text { de } \\
\text { cirurgias pelas } \\
\text { operadas } \\
2.417 \mathrm{DH}\end{array}$ & $\begin{array}{c}\% \text { cirurgias } \\
\text { por graus } \\
\text { de } \mathrm{DH}\end{array}$ \\
\hline Grau I & 1.135 & $12,2 \%$ & 0 & $0 \%$ & 0,0 & $0 \%$ \\
\hline Grau II & 2.625 & $28,3 \%$ & 170 & $1,8 \%$ & 7,0 & $6,5 \%$ \\
\hline Grau III & 3.429 & $36,9 \%$ & 1.046 & $11,3 \%$ & 43,3 & $30,5 \%$ \\
\hline Grau IV & 1.883 & $20,3 \%$ & 1.134 & $12,2 \%$ & 46,9 & $60,2 \%$ \\
\hline Plicomas & 217 & $2,3 \%$ & 67 & $0,7 \%$ & 2,8 & $30,9 \%$ \\
\hline Total & 9.289 & $100,0 \%$ & 2.417 & $26,0 \%$ & 100,0 & 100,0 \\
\hline
\end{tabular}

Foi a seguinte a distribuição das DAC entre os 2.417 pacientes operados de DH: em 2.417 pacientes operados de DH, $729(30,1 \%)$ foram operados de outras doenças anais, destacando-se $13,1 \%$ (317 pacientes) de fissura anal, 11,0\% (267 pacientes) de hipertrofia de papilas anais, 3,7\% (89 pacientes) de fístula anal, 1,3\% (31 pacientes) de hipotonia anal com incontinência anal parcial, $0,9 \%$ (22 pacientes) de condilomas anais acuminados e
$0,1 \%$ ( 3 pacientes) de tumores anais malignos (Tabela-7 e Figura-9).

Foi a seguinte a relação entre os portadores de DAC diagnosticadas e DAC operadas: 317 dos 541 casos de fissuras anais foram operadas $(58,6 \%)$, da mesma forma que 267 dos 312 casos de hipertrofia de papilas anais $(85,6 \%), 89$ dos 117 casos de fístulas anais $(76,1 \%), 31$ dos 112 casos de hipotonia anal com incontinência anal parcial (27,7\%), 22 dos 37 casos

Tabela 7 - Incidência de doenças anais concomitantes (DAC) à doença hemorroidária $(D H)$ em um universo de 9.289 pacientes $(1.122 ; 12,1 \%)$, destacando-se: fissura anal, hipertrofia de papila anal, fístula anal, hipotonia anal, condiloma anal acuminado e tumor perianal; incidência relativa e absoluta de doenças anais concomitantes (DAC) operadas em concomitância à hemorroidectomia (729 cirurgias em 2.417 pacientes operados de DH, 65,0\%); e incidência de DAC operadas e DAC diagnosticadas.

\begin{tabular}{lcccccc}
\hline $\begin{array}{l}\text { Doenças anais } \\
\text { concomitantes }\end{array}$ & $\begin{array}{c}\text { N relativo } \\
\text { a } \mathbf{9 . 2 8 9}\end{array}$ & $\begin{array}{c}\text { \% relativo } \\
\mathbf{a} \text { 9.289 }\end{array}$ & $\begin{array}{c}\text { \% relativo } \\
\mathbf{a ~ 1 . 1 2 2}\end{array}$ & $\begin{array}{c}\text { N de } \\
\text { pacientes } \\
\text { operados }\end{array}$ & $\begin{array}{c}\text { \% de } \\
\text { pacientes } \\
\text { operados }\end{array}$ & $\begin{array}{c}\text { \% DAC } \\
\text { operada } \\
\text { e diagnosticada }\end{array}$ \\
\hline Fissura anal & 541 & $5,8 \%$ & $48,2 \%$ & 317 & $13,1 \%$ & $58,6 \%$ \\
Hipertrofia de papilas anais & 312 & $3,4 \%$ & $27,8 \%$ & 267 & $11,0 \%$ & $85,6 \%$ \\
Fístula anal & 117 & $1,3 \%$ & $10,4 \%$ & 89 & $3,7 \%$ & $76,1 \%$ \\
Hipotonia esfincteriana & 112 & $1,2 \%$ & $10,0 \%$ & 31 & $1,3 \%$ & $27,7 \%$ \\
Condiloma anal acuminado & 37 & $0,4 \%$ & $3,3 \%$ & 22 & $0,9 \%$ & $59,5 \%$ \\
Tumor perianal & 3 & $0,03 \%$ & $0,3 \%$ & 3 & $0,1 \%$ & $100,0 \%$ \\
Total & 1.122 & $12,1 \%$ & $100,0 \%$ & 729 & & \\
\hline
\end{tabular}


de condilomas anais acuminados $(59,5 \%)$ e os 3 casos de tumores perianais diagnosticados $(100,0 \%)$ (Tabela 7 e Figura-9).

\section{DISCUSSÃO}

INCIDÊNCIA ABSOLUTA DA DH: Há muita controvérsia sobre a epidemiologia da $\mathrm{DH}$, e vários trabalhos têm sido publicados com referência ao estudo da incidência absoluta de DH na população $5,12,19,21,27,34,35,37$. As disparidades decorrem do uso de metodologias completamente diversas, que vão desde a denominação de $\mathrm{DH}$ a doenças sintomáticas a achados fortuitos e mesmo achados de necropsias. Alguns autores admitem incidências de DH na população com variações muito conflitantes, que incluem incidências médias que vão de um extremo de 4,4\% - Loder et al. (1994) ${ }^{22}$ a $86 \%$ da humanidade - Hass et al. (1983) ${ }^{16}$. Tal fato faz concluir o uso de metodologias completamente diversas, e que pode eivar de erros conclusões precipitadas, pois vão desde a denominação para a DH sintomática até achados de necrópsias. Em estudo comparativo entre grupos sintomáticos e assintomáticos, Hass et al. $(1983,1984)$ relatam uma incidência bastante semelhante, com identificação de hemorróidas em $88 \%$ no grupo sintomático (DH), e $82 \%$ no grupo assintomático (submetido a exame proctológico de rotina para rastreamento de câncer colorretal ou por solicitação de outras clínicas).

No decurso de 38 anos de profissão com prática totalmente centrada em Coloproctologia, o

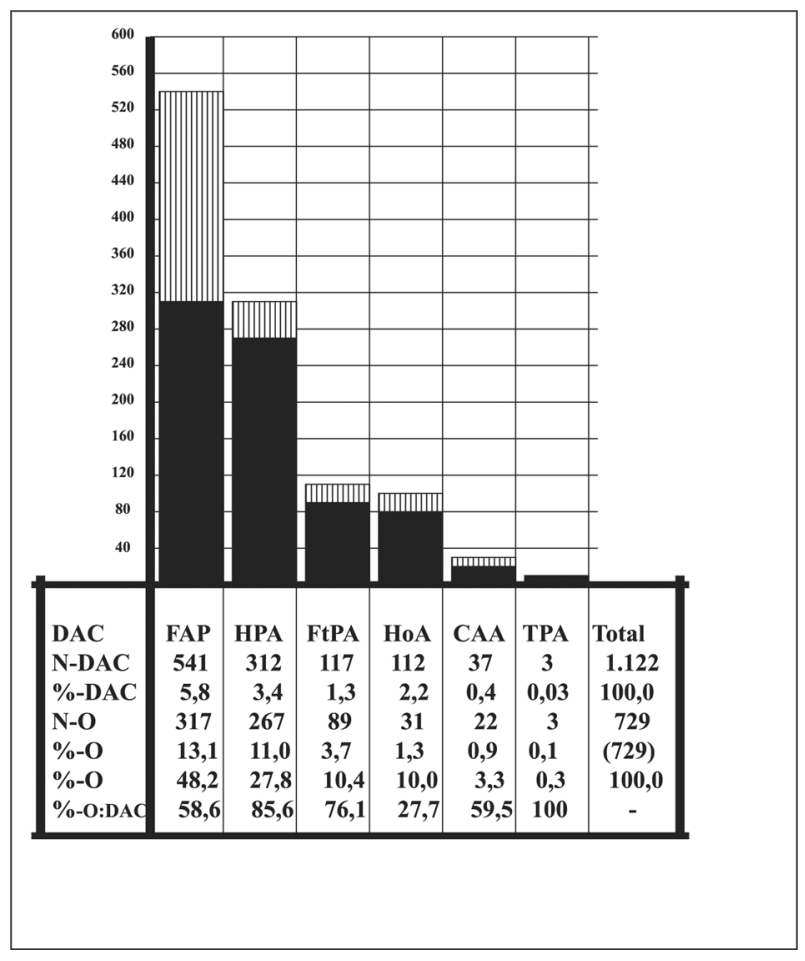

Figura 9 - Incidência de doenças anais concomitantes $(D A C)$ à doença hemorroidária $(D H)(1.122 ; 12,1 \%)$ em um universo de 9.289 pacientes, destacando-se: fissura anal (FAP), hipertrofia de papila anal (HPA), fístula perianal (FtPA), hipotonia anal (HoA), condiloma anal acuminado (CAA) e tumor perianal (TPA), representadas pelas colunas listradas, em números absolutos $(N-D A C)$ e percentuais $(\%-$ $D A C)$; e incidência relativa e absoluta de doenças anais operadas em concomitância à hemorroidectomia (729 cirurgias em 2.417 pacientes operados de DH, 65,0\%), representadas pelas colunas sobrepostas em negrito, em números absolutos ( $\mathrm{N}-\mathrm{O})$ e percentuais (\%-O); e incidência de DAC operadas e DAC diagnosticadas, absoluto (\%-O) e relativo (\%DAC-O). 
primeiro autor teve a oportunidade de formar um fichário constituído de 34.000 pacientes, tendo feito diagnóstico de $\mathrm{DH}$ como doença de fundo e motivo da consulta, em 9.289 pacientes $(27,32 \%)$ e operado 2.417 deles (Tabela-2 e Figura-1), o que significa que foram atendidos 894 novos pacientes por ano ou 74 novos pacientes ao mês ou 16 novos pacientes por semana, diagnosticando-se um caso de DH em cada 3,6 pacientes atendidos, como doença que motivou a consulta. Não há como aferir nossos achados com os da literatura, devido aos parâmetros díspares utilizados pelos vários autores.

INCIDÊNCIA DE DH POR SEXO: Em relação aos 9.289 pacientes portadores de $\mathrm{DH}$ predominou, de forma estatisticamente significativa, a incidência de DH entre mulheres (5.007 ou 53,9\%) sobre homens (4.282 ou 46,1\%); e predominou, mas sem significado estatístico, a incidência de cirurgias entre as mulheres portadoras de DH (1.330: 5.007 ou $26,6 \%$ ) sobre cirurgias em homens portadores de $\mathrm{DH}$ ( $1.087: 4.282$ ou $25,4 \%)$. Todavia, quando relacionada aos 2.417 pacientes operados, a incidência de cirurgia foi, de forma estatisticamente significativa mais comum entre as mulheres ( $1.330: 2.417$ ou $55,0 \%)$ que entre os homens ( $1.087: 2.417$ ou $45,0 \%$ (Tabela3 e Figuras-2 e 3).

Embora a maioria dos autores admita predominância da $\mathrm{DH}$ no homem ${ }^{12}$, 19, 21, 27, 34, 35, há relatos de incidências maiores no sexo feminino $5,9,10$, 12, 37. Assim, nossos achados não coincidem com os relatos da maioria dos autores. Santos (1999) ${ }^{34,35}$, em sua experiência pessoal com 1.327 portadores de hemorróidas, encontrou 768 homens $(57,87 \%)$ e 559 mulheres $(42,13 \%)$, portanto contrário aos nossos achados.

INCIDENNCIA POR IDADES: Em nosso material (Tabela-4 e Figura-4) verifica-se que a distribuição da DH por faixas etárias, entre os 9.289 pacientes estudados, privilegiou a terceira $(21,0 \%$, 1.957 pacientes), quarta $(30,4 \%, 2.820$ pacientes $)$ e quinta décadas $(23,4 \%, 2.172$ pacientes $)$, totalizando $74,8 \%$, com média etária global de 39,9 anos.

Como se pode ver na Tabela-4 e na Figura-5, as décadas etárias dos 2.417 pacientes por ocasião da cirurgia que mais se fizeram presentes foram as mesmas décadas, ou seja: terceira $(20,8 \%, 502$ pacientes), na quarta $(28,5 \%, 688$ pacientes $)$ e a quinta décadas $(22,5 \%, 543$ pacientes), totalizando $71,8 \%$, com média etária global de 41,6 anos.

Fazendo-se uma comparação, por décadas, entre os pacientes portadores de $\mathrm{DH}$ e dos pacientes submetidos à hemorroidectomia, constatam-se (Tabela- 4 e Figura- 6) percentuais muito semelhantes entre pacientes portadores de $\mathrm{DH}$ e pacientes operados de DH. É interessante ressaltar que os percentuais de cirurgias por décadas superaram os percentuais de diagnóstico por décadas na terceira, quarta, quinta, sexta e décima décadas, enquanto os percentuais de cirurgia superaram os percentuais de diagnóstico apenas na primeira, sétima, oitava e nona década, mas em todas as eventualidades, sem diferenças estatisticamente significativas.

São raríssimos relatos de ocorrências de $\mathrm{DH}$ na infância e muito pouco freqüentes antes dos 20 anos de idade, admitindo, a maioria dos autores 5,12 , 19, 21, 27, 34, 35, 37 incidências mais elevadas entre $30 \mathrm{e}$ 60 anos 5, 9, 10, 12, 18, 19, 21, 22, 23, 27, 34, 35, 37. Após os 60 anos, com a diminuição de alguns fatores desencadeantes, a incidência decresce, cedendo lugar ao aparecimento de doenças relacionadas à diminuição do tônus muscular pelviperineal e do assoalho pélvico, tendo Santos (1999) ${ }^{34,35}$, em 1.327 portadores de DH encontrado 53,96\% dos casos em pacientes entre 31 e 50 anos e $70,0 \%$ entre 31 e 60 anos. Destarte nossos resultados coincidem com os relatos da literatura.

SINTOMATOLOGIA E DIAGNÓSTICO:

O diagnóstico é feito, como assinalam os autores, a partir da sintomatologia e do exame proctológico, não havendo exames complementares para diagnóstico desta doença. Os sintomas mestres são o prolapso e o sangramento, mas, com o tempo, outros vão surgindo: sensações anorretais fora do ato defecatório (presença de mamilos anais, dermatite irritativa, dor em pontada, em ardência, latejante, em pressão; sensação de pressão retal, sensação de plenitude retal, secreção fecal, mucosa e sangue nas roupas), sensações ao ato defecatório (dificuldade, dor, exteriorização com redução espontânea ou manual, sensação de evacuação incompleta). O diagnóstico de $\mathrm{DH}$ ao exame proctológico, como assinala a maioria dos autores consultados, não autoriza o final do exame, que deve ser completo - inspecção, apalpação, toque e retossigmoidoscopia, além de manobras de esforço). 
Doença Hemorroidária - Aspectos Epidemiológicos e Diagnósticos de 9.289 Pacientes Portadores de Doença Hemorroidária

Geraldo Magela Gomes da Cruz e Cols.
Vol. 26
Dentre as complicações mais freqüentes podem ser destacados as tromboses, os estrangulamentos, as hemorragias e as ulcerações com infecção secundária e os abscessos. Os sintomas mais comuns descritos pelos pacientes (amostra dos 200 últimos da série de 9.289) foram (Tabela-5 e a Figura-7): mamilos anais (181 casos, 90,5\%), sangue nas fezes (166 casos, 83,0\%), exteriorização pelo ânus ao ato defecatório (142 casos, $71,0 \%)$, ardência anal (112 casos, 54,0\%), escape (soiling) (88 casos, 44,0\%) e sangue nas roupas (62 casos, $41,0 \%$ ). São sintomas antológicos, por demais decantados por todos os autores $5,7,8,9,10,14,19,21,27,34,35,37$ como as queixas mais comuns em pacientes portadores de DH. A sintomatologia é traduzida pelos graus de evolução das hemorróidas internas e partes internas das hemorróidas mistas: grau I (os coxins ou mamilos hemorroidários se apresentam congestos e intumescidos e podem sangrar sem haver exteriorização), grau II (os coxins ou mamilos internos se prolabam, projetando-se externamente ao ânus durante o esforço da defecação, entretanto recolhem-se espontaneamente após a cessação do esforço defecatório, podendo apresentar sangramento associado), grau III (os mamilos apresentam um volume maior e se prolabam mais facilmente com o esforço, de forma que o seu retorno à parte interna é sempre muito lento com auxílio de manobras manuais), grau IV (o volume dos mamilos e a flacidez dos tecidos são tão acentuados que o prolapso se torna incoercível, com a intitulada "perda de domicílio dos mamilos hemorroidários internos", que se apresentam permanentemente exteriorizados, apresentando macerações e erosões importantes do revestimento mucoso). Os sintomas que encontramos entre a amostra dos 200 pacientes estão coerentes com os relatos de outros autores ${ }^{5,7}$, $8,9,10,14,19,21,27,34,35,37$.

\section{DISTRIBUIÇÃO DOS PACIENTES PELO DIAGNÓSTICO E ABORDAGEM CIRÚRGICA DE ACORDO COM A GRADACÃO DADH: Quanto} à localização anatômica, a DH pode ser classificada em "interna" (submucosa anorretal acima do ligamento de Parks, recobertas por epitélio mucoso), "externas" (abaixo do ligamento de Parks, recobertas por pele modificada do canal anal) e "mistas" (extensão internas e externas). Quanto à sintomatologia a DH é classificada em graus de evolução que se referem aos estágios de evolução das hemorróidas internas e partes internas das hemorróidas mistas: hemorróidas grau I (os coxins ou mamilos hemorroidários se apresentam congestos e intumescidos e podem sangrar sem haver exteriorização), hemorróidas grau II (os coxins ou mamilos internos se prolabam, projetando-se externamente ao ânus durante o esforço da defecação, entretanto recolhem-se espontaneamente após a cessação do esforço defecatório, podendo apresentar sangramento associado), hemorróidas grau III (os mamilos apresentam um volume maior e se prolabam mais facilmente com o esforço, de forma que o seu retorno à parte interna é sempre muito lento com auxílio de manobras manuais), hemorróidas grau IV (o volume dos mamilos e a flacidez dos tecidos são tão acentuados que o prolapso se torna incoercível, com a intitulada "perda de domicílio dos mamilos hemorroidários internos", que se apresentam permanentemente exteriorizados, apresentando macerações e erosões importantes do revestimento mucoso).

A distribuição das várias formas de DH entre os 9.289 pacientes foi a seguinte: primeiro grau em 1.135 pacientes $(12,2 \%)$, segundo grau em 2.625 pacientes $(28,3 \%)$, terceiro grau em 3.429 pacientes (36,9\%), quarto grau em 1.883 pacientes $(20,3 \%)$ e plicomas anais ou hemorróidas externas em 217 pacientes $(2,3 \%)$ (Tabela- 6 e Figura-8). No tocante à incidência de cirurgias pela gradação da $\mathrm{DH}$ foi a seguinte a distribuição dos pacientes: $0 \%$ do primeiro grau (nenhum paciente operado entre os 1.135 pacientes); $6,5 \%$ do segundo grau (170 cirurgias em 2.625 pacientes), $30,5 \%$ do terceiro grau (1.046 cirurgias em 3.429 pacientes), 60,2\% do quarto grau (1.134 cirurgias em 1.883 pacientes) e $30,9 \%$ dos plicomas anais (67 cirurgias em 217 pacientes) (Tabela- 6 e Figura-8). No tocante aos vários graus e formas de DH operadas em relação ao total de pacientes portadores de $\mathrm{DH}$ (9.289), foram operados, dos 9.289 portadores de $\mathrm{DH}, 2.417$ pacientes $(26,0 \%)$, sendo $0 \%$ do primeiro grau, $1,8 \%$ do segundo grau (170 pacientes), $11,3 \%$ do terceiro grau (1.046 pacientes), $12,2 \%$ do quarto grau (1.134 pacientes operados) e $0,7 \%$ de plicomas anais ou hemorróidas externas (67 pacientes operados) (Tabela- 6 e Figura-8). No que se refere aos graus e formas de DH operadas em relação ao total de 
cirurgias para DH (2.417 pacientes), nota-se que o grau de DH mais operado foi o grau IV, com 1.134 pacientes $(46,9 \%)$, seguido de perto pelas DH grau III, com 1.046 pacientes (43,3\%) (Tabela- 6 e Figura8 ). No que se refere aos vários graus de $\mathrm{DH}$ operadas em relação aos próprios graus da doença, verifica-se que quanto mais avançada a DH mais pacientes optaram pela cirurgia: $60,2 \%$ dos 1.883 pacientes portadores de DH de quarto grau (1.134) foram operados, seguindo-se o grau imediatamente subseqüente, o terceiro grau, em que 30,5\% (1.046 pacientes) dos 3.429 pacientes foram operados (Tabela- 6 e Figura-8).

Nota-se que, à exceção da incidência de cirurgia nos pacientes portadores de plicomas anais nos quais prevaleceram o fator estético ou a incômoda presença de uma "pele mais exuberante" ou a dificuldade de higiene anal - que nenhum ou quase nenhum sintoma trazia, (dos 217 pacientes portadores de plicomas anais 67 ou 30,9\% optaram pela cirurgia), o fator que mais levou o paciente à cirurgia foi a sintomatologia, fato que coincide com os relatos de vários autores 7, 11, 12, 32,34,35.

OUTRAS DOENCAS ANAIS CONCOMITANTES À DH ABORDADAS EM CONJUNTO COM A CIRURGIA HEMORROIDÁRIA: É comum

a associação de DH com outras doenças anais, merecendo destaques as fissuras, além de outras menos incidentes, como as papilites, as criptites, as fístulas, os prolapsos, os condilomas e os pólipos. Diagnósticos concomitantes ao diagnóstico da $\mathrm{DH}$, por ocasião do exame proctológico, como doenças paralelas ou secundárias, foram feitos em 1.122 pacientes $(12,1 \%)$ (Tabela-7 e Figura -9), destacando-se 541 (5,8\%) casos de fissuras anais, seguindo-se $312(3,4 \%)$ casos de hipertrofia de papilas anais, $117(1,3 \%)$ casos de fístula anal, $112(1,2 \%)$ casos de hipotonia anal com incontinência parcial, $37(0,4 \%)$ casos de condilomas anais acuminados e $3(0,03 \%)$ de tumores perianais. A incidência destas doenças anais concomitantes é assinalada por vários autores $9,10,24,25,34,35,37$, o que coincide com nossos relatos.

A proporção entre os 1.122 casos de doenças anais concomitantes à DH foi seguinte: 48,2\% (541 casos) eram fissuras anais, 27,8\% (312 casos) eram hipertrofia de papilas anais, $10,4 \%$ (117 casos) eram fístulas anais, 10,0\% (112 casos) eram hipotonia anal com incontinência parcial, 3,3\% (37 casos) eram condilomas anais acuminados e $0,3 \%$ ( 3 casos) eram tumores anais malignos (Tabela-7 e Figura 9). Esta proporção, embora não assinalada pelos autores consultados, deve corresponder à realidade, haja vista o elevado volume dos casos de nosso registro. Entre os 2.417 pacientes operados de DH, $729(30,1 \%)$ foram operados também de outras doenças anais concomitantes, destacando-se fissura anal $(13,1 \%, 317$ pacientes), hipertrofia de papilas anais $(11,0 \%, 267$ pacientes $)$, fístulas anais $(3,7 \%$, 89 pacientes), hipotonia anal com incontinência anal parcial $(1,3 \%, 31$ pacientes $)$, condilomas anais acuminados $(0,9 \%, 22$ pacientes $)$ e tumores anais malignos $(0,1 \%, 3$ pacientes) (Tabela-7 e Figura9). A incidência de 100,0\% (3 casos diagnosticados e operados) decorreu, certamente, da natureza possivelmente maligna da lesão encontrada; as demais incidências de DAC operadas e diagnosticadas decorrem dos sintomas que as mesmas acrescentam aos sintomas decorrentes da $\mathrm{DH}$ : $58,6 \%$ das fissuras anais diagnosticadas foram operadas; da mesma forma que $85,6 \%$ das hipertrofias de papilas anais, $76,1 \%$ das fístulas anais, $27,7 \%$ das hipotonias anais com incontinência anal parcial, $59,5 \%$ dos condilomas anais acuminados e $100,0 \%$ dos tumores perianais (Tabela-7 e Figura -9). Deve ser enfatizado que todos os casos de DAC foram diagnósticos secundários ao diagnóstico de $\mathrm{DH}$.

\section{CONCLUSÕES}

1. A incidência de DH em consultório de Coloproctologia foi de 27,3\% (9.289 casos de DH em 34.000 pacientes ou $1: 3,6$ pacientes).

2. A incidência de hemorroidectomia (2.417) entre portadores de DH (9.289) foi de 26,0\%.

3. A incidência de DH foi, de forma estatisticamente significativa, maior entre mulheres (5.007 : 9.289 ou $53,9 \%)$ que entre homens $(4.282: 9.289$ ou $46,1 \%)$.

4. A incidência de hemorroidectomia entre as mulheres portadoras de DH (1.330 : 5.007) foi, sem significado estatístico, maior $(26,6 \%)$ que entre homens $(25,4 \%)$ portadores de DH (1.087 : 4.272). 
5. A incidência de hemorroidectomia, em termos absolutos, foi, de forma estatisticamente significativa, maior entre as mulheres (1.330:2.417, $55,0 \%)$ que entre os homens $(1.087: 2.417$, $45,0 \%)$.

6. A média etária de incidência de DH foi de 39,9 anos, com as maiores incidências $(74,8 \%)$ entre 21 e 50 anos.

7. A média etária de hemorroidectomia foi de 41,6 anos, com as maiores incidências $(71,8 \%)$ entre 21 e 50 anos.

8. Os principais sintomas (amostra de 200 pacientes consecutivos) foram mamilos anais (181 casos; $90,5 \%$ ), sangue nas fezes e/ou no papel higiênico (166 casos; 83,0\%), exteriorização anal ao defecar (142 casos; 71,0\%) e ardência anal (112 casos; $56,0 \%)$.

9. As maiores incidências de gradações de DH diagnosticada foram as de terceiro (3.429 casos,
$36,9 \%)$ e quarto $(2.625$ casos, $28,3 \%)$ graus $(65,2 \%, 6.054$ casos $)$.

10. As maiores incidências relativas de gradações de DH operadas foram as de quarto grau (1.134: 1.883, $60,2 \%)$, seguindo-se os plicomas $(67: 217,30,9 \%)$ e as de terceiro grau $(1.046: 3.429,30,5 \%)$.

11. As maiores incidências absolutas de gradações de DH operadas foram as de quarto grau (1.134 : $2.417,46,9 \%)$, seguindo-se as de terceiro grau $(1.046: 2.417,43,3 \%)$.

12. A incidência de doenças anais concomitantes à DH foi de $12,1 \%$ (1.122: 9.829), sendo a fissura anal a mais comum (541 casos, 5,8\%), seguida pela hipertrofia de papilas anais (312 casos, 3,4\%).

13. A incidência de doenças anais concomitantes operadas em conjunto com a DH foi de $30,1 \%$ (729: 2.417, destacando-se a fissurectomia anal $(13,1 \%, 317$ pacientes) e a papilectomia $(11,0 \%$, 267 pacientes).

SUMMARY: In a 38-year period of practice in Coloproctology, from 1965 to 2003 , the author had the opportunity to attend 34,000 patients. Diagnose of hemorrhoids as the main cause of the symptoms presented was achieved in 9,289 patients $(27.3 \%) .2,417$ of the $\mathbf{9 , 2 8 9}$ patients $(\mathbf{2 6 . 0 0 \%})$ were submitted to hemorroidectomy. The aim of this report is to analyse these patients as far as epidemiologic aspects are concerned: age, gender, classification and grade of hemorrhoids, symptoms and proctologic findings as well as concomitant anorectal diseases and surgical treatment.

As far as gender is concerned the incidence of hemorrhoids was statistically significant higher among women $(5,007$ cases, $53.9 \%)$ than in men $(4,282$ cases, $46.1 \%)$. And although not statistically significant surgery for hemorrhoids for women $(1,330$ : $5,007)$ was more common $(26.6 \%)$ than in men $(1,087: 4,282)(25.4 \%)$. But in relation to the patients who underwent hemorrhoidectomy $(2,417)$ the surgery was statistically significant more commom among women $(1,330: 2,417$ or $55.0 \%)$ than in men $(1,087$ : 2,417 or $45.0 \%)$.

Mean age of the patients by occasion of diagnose of hemorrhoids was 39.9 year, being $74.8 \%$ between 21 and 50 year of age. Mean age by occasion of surgery was 41.6 year, being $71.8 \%$ between 21 and 50 year of age.

The most frequent symptoms presented by the patients were anal piles $(90.5 \%)$, blood in the stools $(83.0 \%)$, rectal exteriorization during defecation $(\mathbf{7 1 . 0 \%})$ and anal pain $(\mathbf{5 4 . 0 \%})$.

As far as graduation of the disease is concerned, third grade hemorrhoids was more common (36.9\%), following second $\mathbf{2 8 . 3 \%})$ and fourth $(\mathbf{2 0 . 3} \%)$ grades. Surgery was more common in fourth grade hemorrhoids $(\mathbf{6 0 . 2 \%})$, following anal external piles $(30.9 \%)$ and third grade hemorrhoids $(30.5 \%)$.

In 1,122 patients hemorrhoids were associated with several anore ctal diseases $(\mathbf{1 2 . 1 \%})$, with emphasis to anal fissures $\mathbf{( 5 . 8 \% )}$ and hyperthrofied anal papila $(3.4 \%)$. The incidence of surgery for associated anorectal disease was $13.1 \%$ (729 patients), being fissurectomy $(\mathbf{1 3 . 1 \%})$ and papilectomy $(\mathbf{1 1 . 0 \%})$ the two more frequently surgery carried out during hemorroidal approach.

Key words: Hemorroidal disease, Hemorrhoids, Hemorrhoidectomy, Epidemiology, Anal diseases

\section{REFERÊNCIAS BILIOGRÁFICAS}

1. Ahmed SK, Thomson HJ: The effect of breakfast on minor anal complaints: a matched case-control study. J R Coll Surg Edinb. 1997; 42: 331-3.
2. Barone B, Matos D, Deak, Saad SS: Hemorroidectomia com o uso de diatermia e sem ligadura do pedículo. Atualização em Coloproctologia 1995: 203-5. 
3. Barron (1962). In: Rebel K, Rebel VF. Tratamento Não Cirúrgico da Doença Hemorroidária. In: Cruz GMG. Livro Texto "Coloproctologia", Vol. III - "Coloproctologia Terapêutica”. Rio de Janeiro, Editora Revinter. 2000; 165: 2141-7.

4. Blaisdell (1954). In: Rebel K, Rebel VF. Tratamento Não Cirúrgico da Doença Hemorroidária. In: Cruz GM. Livro Texto "Coloproctologia", Vol. III - "Coloproctologia Terapêutica”. Rio de Janeiro, Editora Revinter. 2000; 163 : 2141-7.

5. Borba MR, Sobrado CW Jr, Sokol S: Hemorroidectomia pela técnica fechada (Técnica de Sokol) - análise de 322 doentes. Rev Bras Coloproct. 1997; 17: 98-100.

6. Buls JG, Goldberg SM: Modern management of hemorrhoids. Surg Clin North Am. 1978; 58: 469-78.

7. Cope R: Etiopathogenesis of hemorrhoidal disease. Acta Gastroenterol Belg. 1994; 57: 206-12.

8. Corman ML: Colon \& Rectal Surgery ( $4^{\text {th }}$ ed.), LippincortRaven, Publishers. 1998.

9. Cruz GMG: Livro Texto "Coloproctologia", Vol. II "Coloproctologia - Propedêutica Nosológica". Rio de Janeiro, Editora Revinter. 1999.

10. Cruz GMG. Livro Texto "Coloproctologia", Vol. III "Coloproctologia - Terapêutica". Rio de Janeiro, Editora Revinter. 2000

11. Ferguson JA, Heaton JR: Closed hemorrhoidectomy. Dis Colon Rectum. 1959; 2: 176-9.

12. Ganchrow MI, Mazier WP, Friend WG, Ferguson JA Hemorrhoidectomy revisited-a computer analysis of 2,038 cases. Dis Colon Rectum. 1971; 14: 128-33.

13. Goldstein ET, Williamson PR, Larach SW: Subcutaneous morphine pump for postoperative hemorrhoidectomy pain management. Dis Colon Rectum. 1993; 36: 439-46.

14. Goligher J: Surgery of the Anus, Rectum and Colon. $\left(5^{\text {th }} \mathrm{ed}.\right)$, London: Bailieri -Tindall. 1984.

15. Haas PA, Fox TA Jr, Haas GP: The pathogenesis of hemorrhoids. Dis Colon Rectum. 1984; 27: 442-50.

16. Haas PA, Haas GP, Schmaltz S, Fox TA Jr: The prevalence of hemorrhoids. Dis Colon Rectum. 1983; 26: 435-9.

17. Ho YH, Seow-Choen F, Low JY, Tan M, Leong AP: Randomized controlled trial of trimebutine (anal sphincter relaxant) for pain after haemorrhoidectomy. Br J Surg. 1997; 84: 377-9.

18. Hodgson WJ, Morgan J: Ambulatory hemorrhoidectomy with CO2 laser. Dis Colon Rectum. 1995; 38: 1265-9.

19. Iwagaki H, Higuchi Y, Fuchimoto S, Orita K: The laser treatment of hemorrhoids: results of a study on 1816 patients. Jpn J Surg. 1989; 19: 658-61.

20. Jensen DM, Jutabha R, Machicado GA, Jensen ME, Cheng $\mathrm{S}$, Gornbein J, et al.: Prospective randomized comparative study of bipolar electrocoagulation versus heater probe for treatment of chronically bleeding internal hemorrhoids. Gastrointest Endosc. 1997; 46: 435-43.
21. Lacerda Filho A, Melo Jr C: Hemorroidectomia em regime ambulatorial sob anestesia local - estudo prospectivo de 50 casos. Rev Bras Coloproct. 1995; 15: 206-10.

22. Loder PB, Kamm MA, Nicholls RJ, Phillips RK: Haemorrhoids: pathology, pathophysiology and aetiology. $\mathrm{Br}$ J Surg. 1994; 81: 946-54.

23. MacRae HM, McLeod RS: Comparison of hemorrhoidal treatment modalities. A meta-analysis. Dis Colon Rectum. 1995; 38: 687-94.

24. Mazier WP: Hemorrhoids, fissures, and pruritus ani. Surg Clin North Am. 1994; 74: 1277-92.

25. McConnell JC, Khubchandani IT: Long-term follow-up of closed hemorrhoidectomy. Dis Colon Rectum. 1983; 26: $797-$ 9.

26. Milligan ET, Morgan CN, Jones LE: Surgical anatomy of the anal canal and the operative treatment of haemorrhoids. Lancet. 1937; 2: 1119-24.

27. Nahas SC, Sobrado CW, Araujo SE, Imperiale AR, Habr-Gama A, Pinotti HW: Resultados do tratamento cirúrgico da doença hemorroidária em 475 doentes. Rev Hosp Clin Fac Med S Paulo. 1997; 52: 175-9.

28. Parks AG: The surgical treatment of haemorrhoids. Br J Surg. 1956; 43: 337-51.

29. Perez-Miranda M, Gomez-Cedenilla A, Leon-Colombo T, Pajares J, Mate-Jimenez J: Effect of fiber supplements on internal bleeding hemorrhoids. Hepatogastroenterology. 1996; 43: $1504-7$

30. Pfenninger JL: Modern treatments for internal haemorrhoids. BMJ. 1997; 314: 1211-2.

31. Randall GM, Jensen DM, Machicado GA, Hirabayashi K, Jensen ME, You S, et al.: Prospective randomized comparative study of bipolar versus direct current electrocoagulation for treatment of bleeding internal hemorrhoids. Gastrointest Endosc. 1994; 40: 403-10.

32. Rebel K, Rebel VF: Tratamento Não Cirúrgico da Doença Hemorroidária. In: Cruz GMG. Livro Texto "Coloproctologia”, Vol. III - "Coloproctologia - Terapêutica". Rio de Janeiro, Editora Revinter. 2000; 163: 2141-7.

33. Reis Neto JA, Quilici FA, Cordeiro F, Reis Junior JA: Open versus semi-open hemorrhoidectomy: a random trial. Int Surg. 1992; 77: 84-90.

34. Santos HA: Doença Hemorroidária. In: Cruz GMG. Livro Texto "Coloproctologia", Vol. II - "Coloproctologia Propedêutica Nosológica”. Rio de Janeiro, Editora Revinter. 1999; 75: 1139-56.

35. Santos RP: Etiopatogenia das hemorróidas. Rev Bras Coloproct. 1993; 13: 55-66.

36. Senagore A, Mazier WP, Luchtefeld MA, MacKeigan JM, Wengert T: Treatment of advanced hemorrhoidal disease: a prospective, randomized comparison of cold scalpel vs. contact Nd:YAG laser. Dis Colon Rectum. 1993; 36: 10429. 
37. Sobrado Jr CW, Bringel RW, Nahas SN, Habr-Gama A: Cirurgia proctológica ambulatorial sob anestesia local - análise de 351 cirurgias. Rev Hosp Clin Fac Med S Paulo. 1998: Vol. VI (novembro/dezembro)

38. Sobrado Jr CW, Bringel RW, Nahas SN. In: Cruz GMG. Livro Texto "Coloproctologia", Vol. III - "Coloproctologia Terapêutica”. Rio de Janeiro, Editora Revinter. 2000; 164: 2148-60.
39. Whitehead W: The surgical treatment of haemorrhoids. BMJ. 1882; 1: 148-50.

\section{Endereço para correspondência:}

Geraldo Magela Gomes da Cruz

Rua Rio de Janeiro, 2017 - Ap. 1401 - Lourdes

30.160-042 - Belo Horizonte (MG) 